Uvodnik/Leading article

\title{
Profesionalna revija kot eden od pomembnih dosežkov nacionalne strokovne organizacije: ob 50. obletnici izhajanja Obzornika zdravstvene nege
}

A journal of professional nursing as one among many accomplishments of the national professional organisation: the 50th anniversary of the Slovenian Nursing Review

\section{Monika Ažman}

Zveza društev medicinskih sester Slovenije je na svoji skupščini leta 1966 sklenila, da bodo trikrat oziroma štirikrat na leto izdajali strokovno glasilo. Z glasilom so napredne članice uredniškega odbora želele zapolniti vrzel v širjenju strokovnih vsebin na področju zdravstva ter si zastavile cilj, da bi glasilo postalo nepogrešljivo za vse, ki jim skrb za zdravje takratnega prebivalstva ne nalaga zgolj poklicna dolžnost, temveč tudi poslanstvo človečnosti. »Izpopolnjevanje znanja je bilo vselej življenjska nujnost za uspešno poklicno delo v zdravstvu in hkrati tudi eno temeljnih društvenih pravil za vse profile zdravstvenih delavcev« so v uvodu v prvi številki Zdravstvenega obzornika leta 1967 zapisale članice uredniškega odbora Cita Bole, Ivana Dolenc, Anica Gradišek in Cilka Potokar (Za uvod, 1967). Zdravstveni obzornik je kot glasilo nadgradil »instruktorskoinformativni list « Medicinska sestra na terenu, ki je izhajal med letoma 1954 in 1961. Tudi v uvodniku prve številke takratnega lista je poudarek na neprestanem strokovnem izpopolnjevanju medicinskih sester, ki je in mora biti prva vzgojiteljica in nepogrešljiva svetovalka (Uvodna beseda, 1954). Skozi leta so se spreminjali uredniški odbori, podoba in oblika besedil, spreminjala se je terminologija in tudi ime glasila. Leta 1994 se je glasilo preimenovalo $\mathrm{v}$ Obzornik zdravstvene nege. $S$ tem je še jasneje opredeljeno strokovno področje, ki mu pripada, več pa je tudi strokovnih informacij in strokovnih člankov, ki so vedno bolj kakovostni ter so rezultat strokovnega in raziskovalnega dela medicinskih sester. Novo tisočletje je prineslo nove napredke na področju informatizacije. Svetovni splet je odprl neslutene možnosti izmenjave podatkov ter poenostavljen dostop do strokovnih člankov in revij $\mathrm{z}$ vsega sveta. Prosto dostopna je tudi znanstvenostrokovna revija Obzornik zdravstvene nege.

$\mathrm{V}$ petdesetih letih je velike spremembe doživela tudi strokovna organizacija. Iz majhne pisarne na
Vidovdanski ulici 9 v Ljubljani smo zrasli v urejeno profesionalno organizacijo, ki je $\mathrm{v}$ tem času zaradi želje po izobraževanju, izboljšanju, nadgradnji kompetenc, znanja in spretnosti pogledala tudi prek slovenskih meja. Priključili smo se Mednarodnemu svetu medicinskih sester (ICN - International Council of Nurses), Svetovni babiški konfederaciji (ICM - International Confederation of Midwives), $\mathrm{v}$ evropskem prostoru pa Evropski federaciji združenj medicinskih sester (EFN - European Federation of Nurses Association) in Evropski babiški zvezi (EMA - European Midwives Association). Zrasla je nova evropska družina - Evropska unija. Zelo smo tudi ponosni, da smo imeli v zadnjih 15 letih slovenskega predstavnika v vodstvu ICN in deset let $\mathrm{v}$ EMA tako majhna, a prepoznavna država, polna delovnih in sposobnih posameznikov. Vse to povezovanje je pomembno vplivalo na strokovni razvoj medicinskih sester in babic v Sloveniji, saj smo začeli uporabljati mednarodne dokumente, predpise, strateške usmeritve mednarodnih organizacij in direktive, pomembne za njihovo izobraževanje in delovanje.

$\mathrm{V}$ vseh desetletjih je največ sprememb doživel prav sistem izobraževanja za zdravstveno nego $\mathrm{v}$ Sloveniji, z njim so se spreminjale tudi kompetence medicinskih sester. Za izobraževanje medicinskih sester je trenutno najpomembnejši dokument EFNsmernice za implementacijo člena 31 o medsebojnem priznavanju poklicnih kvalifikacij glede na Direktivo 2005/36/ Evropske unije, dopolnjeno z Direktivo 2013/55/ Evropske unije. Dopolnjena direktiva o poklicnih kvalifikacijah, sprejeta proti koncu leta 2013, v 31. členu vsebuje osem kompetenc, ki so pravno zavezujoče. Države članice bi morale zagotoviti njihovo implementacijo najpozneje januarja 2016. Narašča namreč spoznanje, da sta učinkovitost zdravstvenega sistema in izboljšanje

Monika Ažman, dipl. m. s.; predsednica, Zbornica zdravstvene in babiške nege - Zveza strokovnih društev medicinskih sester in zdravstvenih tehnikov Slovenije, Ob železnici 30a, 1000 Ljubljana 
zdravja prebivalstva kritično odvisna od ustrezno usposobljene in razporejene zdravstvene delovne sile. Svetovna zdravstvena organizacija $(\mathrm{SZO})$ poroča o napredku $\mathrm{v}$ zadnjih letih pri doseganju ciljev in ciljev globalnega kodeksa zdravstvene prakse na mednarodnem zaposlovanju zdravstvenih delavcev $\mathrm{v}$ evropski regiji in izzivih človeških virov za zdravje 2020. Prav tako poroča o učinkovitem spremljanju tokov zdravstvenih delavcev in boljšem načrtovanju delovne sile, ki je dobro povezano s transformativnim izobraževanjem zdravstvenih delavcev ter učinkovito distribucijo znanja in kombinacijo veščin za izboljšanje splošne učinkovitosti delovne sile v zdravstvu (Buchan \& Perfilieva, 2015).

Na skupnem srečanju ICN, ICM in SZO, ki je potekalo med 17. in 21. majem $2016 \mathrm{v}$ Ženevi, tik pred letno skupščino SZO, so predstavili nov dokument Strateške usmeritve za zdravstveno nego in babištvo 2016-2020 (Global strategic directions for strengthening nursing and midwifery 2016-2020) (World Health Organization, 2016). Namen tega dokumenta je zagotoviti, da bo delovna sila v zdravstveni negi in babištvu učinkovito prispevala $\mathrm{k}$ univerzalni dostopnosti do zdravstvenega varstva za vse uporabnike zdravstvenih storitev znotraj odzivnih zdravstvenih sistemov. „Globalni vpliv zdravstvene nege in babištva še nikoli ni bil bolj potreben, da bi dosegli univerzalno zdravstveno pokritost in trajnostni razvoj tisočletja, « je dejala dr. Frances Hughes, izvršna direktorica ICN (World Health Organization, 2016). $\mathrm{V}$ mnogih državah sta zdravstvena nega in babištvo največja delovna sila $\mathrm{v}$ zdravstvu, zato je naložba $\mathrm{v}$ te poklice bistvena. $V$ teh strateških usmeritvah so ključne štiri teme: zagotavljanje izobraženih, usposobljenih in motiviranih medicinskih sester in babic, ki se bodo učinkovito odzivale na potrebe zdravstvenega sistema na vseh ravneh in $\mathrm{v}$ različnih okoljih; optimizacija razvojne politike, učinkovito upravljanje in vodenje; skupna prizadevanja za povečanje zmogljivosti ter potencialov medicinskih sester in babic skozi intra- in interprofesionalno sodelovanje s partnerji, izobraževanje in stalni strokovni razvoj; mobilizacija politične volje za vlaganje $\mathrm{v}$ gradnjo učinkovitega razvoja delovne sile na področju zdravstvene nege in babištva, ki temelji na znanstvenih dokazih.

Strategija razvoja zdravstvene nege in zdravstvene oskrbe v sistemu zdravstvenega varstva v Republiki Sloveniji za obdobje 2011-2020 (2011) opredeljuje vizijo, izhodiščne usmeritve in strateške cilje razvoja zdravstvene nege. Kot temeljni razvojni dokument opredeljuje vsa področja, ki so skupna in pomembna za delovanje ter razvoj zdravstvene nege in oskrbe na vseh ravneh zdravstvenega varstva in $\mathrm{v}$ vseh delovnih okoljih, in sicer: področje izobraževanja, področje menedžmenta in vodenja, področje informatizacije, pravna ureditev in razvoj dejavnosti zdravstvene nege in oskrbe. V dokumentu je najobširneje opredeljeno prav področje izobraževanja, ki med strateške cilje uvršča izvedbo državne študije, s katero je treba opredeliti potrebe po kadrih na področju zdravstvene nege in oskrbe za najmanj 15-letno obdobje. Prvo petletno obdobje je že minilo, $\mathrm{k}$ izvedbi študije pa država žal še ni pristopila. Možnosti za vertikalno nadgrajevanje strokovnih znanj, za celovit strokovni, karierni in osebnostni razvoj je prek rednih izobraževalnih poti več kot dovolj. Zastavlja se le vprašanje, ali kakovost izobraževalnih institucij na ravni visokošolskega izobraževanja zares prispeva tudi h kakovostni izvedbi izobraževalnih programov in ali diplomanti zadostijo potrebam slovenskega zdravstvenega sistema. Podiplomsko izobraževanje v obliki kliničnih specializacij na posameznih področjih zdravstvene nege mora postati prioriteta pri doseganju ciljev varne in kakovostne zdravstvene obravnave. Zbornica zdravstvene in babiške nege Slovenije Zveza strokovnih društev medicinskih sester, babic in zdravstvenih tehnikov Slovenije (Zbornica - Zveza) je januarja 2016 od ministrstva za zdravje spet prejela javno pooblastilo za načrtovanje specializacij in opravljanje specialističnih izpitov.

Prav zato bo Zbornica - Zveza sledila priporočilu EFN po poenotenih definicijah in klasifikaciji spretnosti, kompetenc, kvalifikacij in poklicev (z enotno terminologijo v vseh jezikih Evropske unije) v zdravstveni negi, z vključitvijo štirih kategorij poklica medicinske sestre. Na podlagi teh je EFN oblikoval matriko in jo začel polniti s ključnimi kompetencami, ki temeljijo na analizi poročila EFN, in sicer za tehnika zdravstvene nege, medicinsko sestro, medicinsko sestro specialistko in medicinsko sestro $\mathrm{z}$ naprednimi znanji. Resolucija o nacionalnem planu zdravstvenega varstva med kratkoročne in srednjeročne izzive umešča tudi načrtovanje kadrovskih virov v državi, ki ne poteka kot usklajen proces med vsemi ključnimi deležniki in ne temelji na ocenah potreb prebivalstva. Posebej poudarjeno je nenačrtovano povečevanje števila visokih šol, ki bi lahko povzročilo neravnovesje na trgu delovne sile, lahko pa pomeni tudi priložnost $\mathrm{v}$ primeru nadaljnjega prenosa kompetenc med zdravstvenimi profili (na primer referenčne ambulante) ali uvajanje novih dejavnosti $\mathrm{v}$ zdravstvu (na primer dolgotrajna oskrba, skupnostna obravnava bolnikov $\mathrm{z}$ duševnimi motnjami ...). Razvoj zdravstvene nege je torej močno povezan in odvisen od razvoja izobraževanja na področju zdravstvene in babiške nege. Magistrski študij na področju zdravstvene nege že poteka, prizadevanja za doktorski študij pa morajo postati realnost že $\mathrm{v}$ tem letu. Napredna znanja, ki jih opredeljujejo vsi pomembni dokumenti, tudi EFN-smernice, so tista znanja, brez katerih ni sodobne obravnave pacienta $\mathrm{z}$ vidika $\mathrm{zdravstvene}$ nege, ki vključuje promocijo zdravja, zdravstveno vzgojo, izvajanje temeljnih življenjskih aktivnosti ter raziskovanje, kakovost in varnost, ki temelji na etiki skrbi. Kot strokovno združenje bomo zagovarjali tudi ustrezno umestitev vseh teh kategorij poklica medicinske sestre v sistemizacijo delovnih mest. 
Glede na dolgoročne izzive na področju zdravja in zdravstvenega varstva $\mathrm{v}$ Sloveniji, ki se dotikajo naraščanja bremena kroničnih bolezni in stanj ter tistih, ki so odvisni od tuje pomoči, povečevanja neenakosti v zdravju, grožnje zdravju, ki jih povzročajo nove nalezljive bolezni, odpornost mikrobov na zdravila in dejavniki iz okolja, finančno vzdržnost zdravstvenih sistemov in mobilnost pacientov, se bo pomembno krepila primarna zdravstvena dejavnost, $s$ katero bi želeli zagotoviti večjo dostopnost do celovite in kakovostne zdravstvene obravnave pacientov (Resolucija o nacionalnem planu zdravstvenega varstva 2015-2025, 2015). Zato je logično pričakovati, da bo ministrica, pristojna za zdravje, sprejela in potrdila programe $\mathrm{z}$ omenjenih področij (krepitev in varovanje zdravja ter preprečevanje bolezni, nujna medicinska pomoč, gerontologija, obvladovanje nalezljivih bolezni in drugih nevarnosti za zdravje, duševno zdravje ipd.).

In kje sta pri vsem zapisanem vloga in pomen Obzornika zdravstvene nege? Osnovno poslanstvo se kljub tehnološkemu napredku, novim medijem ter novim generacijam izvajalcev zdravstvene in babiške nege ni spremenilo. Še vedno ostaja edina in zato še toliko bolj pomembna revija Zbornice - Zveze, ki s svojimi znanstvenimi in strokovnimi vsebinami pomembno vpliva na pridobivanje novih znanj medicinskih sester in babic ter s tem na razvoj zdravstvene in babiške nege $\mathrm{v}$ slovenskem prostoru. Njen pomen je še toliko večji, ker je revija obogatena $z$ gostujočimi tujimi prispevki in ima uredniški odbor z mednarodno zasedbo, hkrati pa je prosto dostopna na svetovnem spletu. Žal ostajajo enaki kot pred petimi desetletji tudi izzivi. Še vedno je premalo kakovostnih člankov, odzivnost nekaterih avtorjev je slaba, nekateri pa se ob prejetju recenzentskih anonimnih mnenj ne strinjajo z objavo. Revija kljub prosto dostopni spletni izdaji še vedno izhaja tudi v tiskani obliki, ker se vodstvo Zbornice - Zveze zaveda, da je tiskana beseda skoraj večna in pomeni dodano vrednost. Žal pa število naročnikov upada in vprašanje časa je, kdaj bo finančno breme tiskane oblike Obzornika zdravstvene nege postalo preveliko in ga bo treba opustiti.

Ob jubileju pa se moramo tudi zahvaliti in pohvaliti sodelujoče pri reviji ter predstaviti nove načrte. Zato vsem dosedanjim urednicam, urednikom, članicam in članom uredniških odborov, lektorjem in lektoricam, tehničnim sodelavcem, tiskarjem in dosedanjim predsednicam stanovske organizacije (Uredništvo skozi čas, 2016) iskrena hvala za vse opravljeno delo, znanje, vztrajnost in prepoznavnost pomembnosti izhajanja revije že dolgih, neprekinjenih petdeset let. $\mathrm{Naj}$ bo ta podatek tudi spodbuda za nadaljnje delo vsem, ki ste $\mathrm{v}$ tem trenutku najtesneje vpeti v izhajanje revije. Iskrene čestitke in najlepše praznovanje $\mathrm{z}$ novimi vsebinami tudi vam, spoštovani bralci.

\section{Literatura}

Buchan, J. \& Perfilieva, G., 2015. Making progress towards health workforce sustainability in the WHO European region. Copenhagen: World Health Organization. Available at:

http://www.euro.who.int/ data/assets/pdf file/0005/287456/ Making-progress-towards-health-workforce-sustainability-inthe-WHO-European-Region-rev1.pdf?ua=1 [30. 5. 2016].

Direktiva 2013/55/EU Evropskega parlamenta in sveta z dne 20. november 2013 o spremembi Direktive 2005/36/ES o priznavanju poklicnih kvalifikacij in Uredbe (EU) št. 1024/2012 o upravnem sodelovanju prek informacijskega sistema za notranji trg (uredba IMI). Uradni list Evropske unije, L 354/132.

Direktiva Evropskega parlamenta in sveta 2005/36/ES z dne 7. septembra 2005 o priznavanju poklicnih kvalifikacij. Uradni list Evropske unije, L 255/22.

Resolucija o nacionalnem planu zdravstvenega varstva 2015 -2025. Skupaj za družbo zdravja. Available at:

http://www.mz.gov.si/fileadmin/mz.gov.si/pageuploads/ PPT 13.6. Resolucija/ResNPZV.pdf [30. 5. 2016].

Strategija razvoja zdravstvene nege in oskrbe $v$ sistemu zdravstvenega varstva $v$ Republiki Sloveniji za obdobje od 2011 do 2020, 2011. Available at:

http://www.zbornica-zveza.si/sites/default/files/doc attachments/strategija razvoja zn 2011-2020 okt 2011.pdf [30. 5. 2016].

Uredništvo skozi čas, 2016. Obzornik zdravstvene nege. Available at: http://www.obzornikzdravstvenenege.si/Urednistvo skozi cas.aspx [30. 5. 2016].

Uvodna beseda, 1954. Medicinska sestra na terenu, 1(1), p. 1. Available at:

http://www.obzornikzdravstvenenege.si/Celoten clanek. aspx?ID=338a9cdb-f9f3-4176-9e9d-f4d81b8b1d50 [30. 5. 2016].

World Health Organization, 2016. Global strategic directions for strengthening nursing and midwifery 2016-2020. Geneva: World Health Organization. Available at:

http://www.who.int/hrh/nursing_midwifery/glob-strategicmidwifery2016-2020 EN.pdf [30. 5. 2016].

Za uvod, 1967. Zdravstveni obzornik, 1(1), pp. 1-2. Available at: http://www.obzornikzdravstvenenege.si/Celoten clanek. aspx?ID=fla3eeb0-95ed-471b-b396-5860141c9868 [30. 5. 2016]. 